\title{
Advances in traceability systems in agri-food supply chains
}

\author{
Samantha Islam ${ }^{1}, *$, Louise Manning ${ }^{2}$, Jonathan M Cullen ${ }^{1}$ \\ ${ }^{1}$ Department of Engineering, University of Cambridge, United Kingdom \\ ${ }^{2}$ Royal Agricultural University, United Kingdom \\ Email: si313@cam.ac.uk ${ }^{1, *, j m c 99 @ c a m . a c . u k}{ }^{1}$, louise.manning@ rau.ac.uk ${ }^{2}$
}

Abstract: Failure to deliver safe and high-quality food reduces consumer confidence in the food industry and results in costly food crises, foodborne illnesses and disruption to food supply chains. Recent advances in traceability systems, and associated identification and communication technologies hold the potential to ensure food quality and safety by managing effective traceability throughout the food supply chains. However, deficits in various factors e.g., resources, awareness, training, standards, data management and technology scaling impede exploitation of these cutting-edge traceability technologies. This chapter provides a review of the advances in agri-food traceability systems and technologies, barriers to their implementations, and possible improvement pathways and policy interventions to promote deployment of advanced food traceability systems.

Key words: Food supply chain, Food traceability system, traceability technologies, barriers of implementation, improvement pathways

\section{Introduction}

Food is a key building block of human physical well-being and consumers' food purchasing behaviour is influenced by three key food characteristics: safety, quality and authenticity (Wilcock et al., 2004; Kendall et al., 2019). However, repetitive occurrence of tragic and costly food crises such as mad cow disease, dioxin contamination, horse meat scandal, Escherichia coli (E. coli) outbreaks and Salmonella contamination not only diminishes consumers' 
24 confidence in food safety, quality and authenticity, but also challenges the underlying credibility of the food industry.

26 The impact of food incidents is amplified by the globalisation of food trade which causes 27 transnational food safety issues (FAO, 2019). According to the World Health Organisation 28 (WHO, 2015), approximately 600 million cases of global illness and 420,000 deaths are caused 29 annually by foodborne diseases, and this leads to considerable economic burden owing to the associated healthcare use, recalls, disposal, and loss of sales and export. As estimated by the United States Department of Agriculture (USDA), the yearly cost of foodborne illnesses in the United States (US) stands at around \$10-83 billion (McLinden et al., 2014), while a single foodborne pathogen, E. coli causes $\$ 14.42$ million in a year for healthcare use in the United

34 Kingdom (UK) (Naylor et al., 2017). On the other hand, border rejections of export consignments result in significant economic loss, for example, owing to the detection of banned antibiotic and Salmonella, seafood supply chains in Asian lower- and middle-income countries are routinely disrupted (Blank, 2018). All these incidents, coupled with a more educated and aware public, underpin increased demand for improved food traceability to communicate the information vis-à-vis food origins, ingredients, processing, quality and safety throughout food supply chains (Rodriguez-Salvador and Dopico, 2020).

41 Food traceability has been defined by many different organisations, in legislation and scientific articles. The commonly used definition from ISO 22005 (ISO, 2005) referring to traceability as: "the ability to follow the movement of a feed or food through specified stage(s) of production, processing and distribution". 


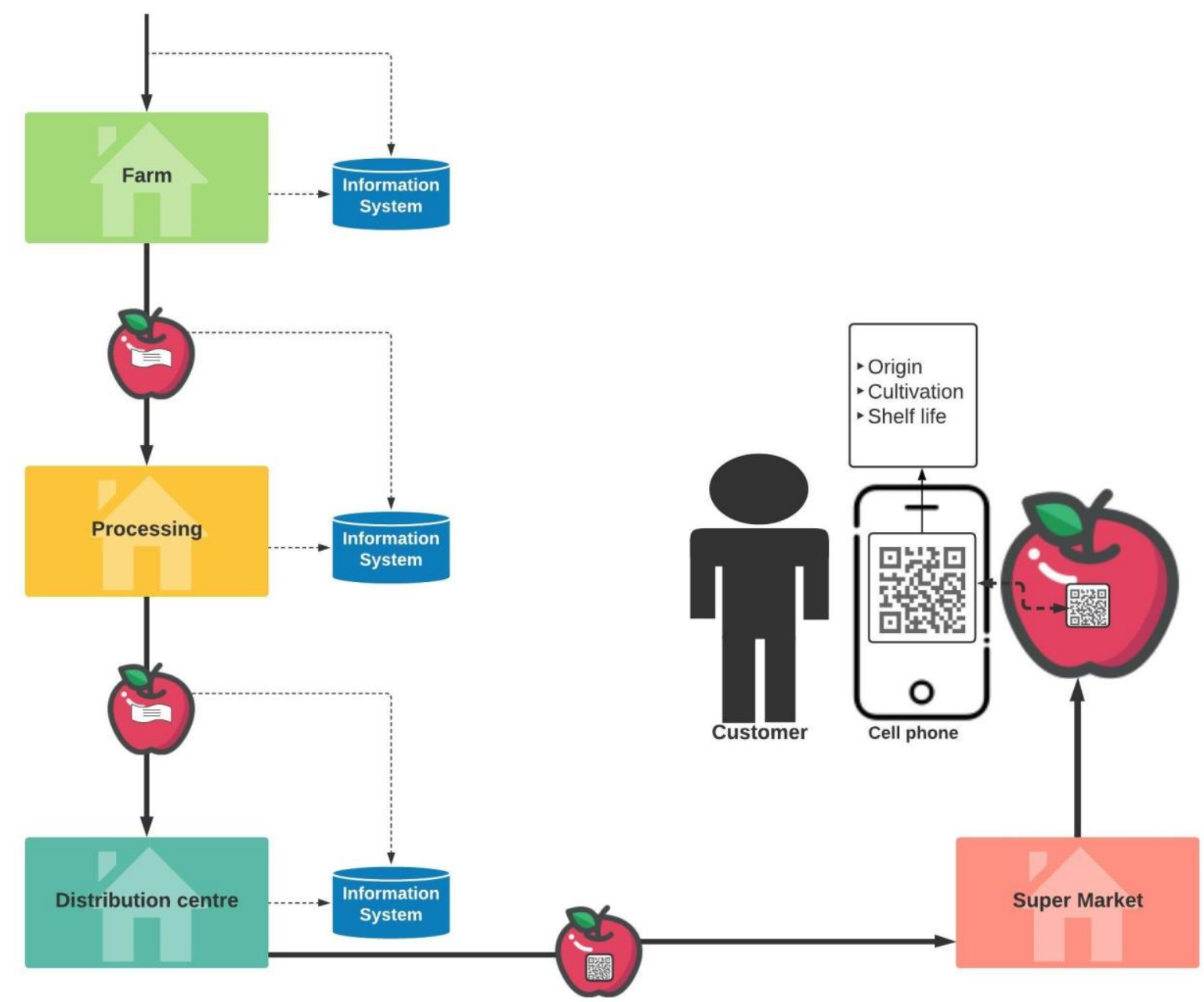

Figure 1.Traceability system in the food supply chain

46 Implementation of food traceability requires the adoption of a food traceability system (FTS)

47 which is a specific arrangement of processes such as, data capture, data storage and data exchange that is capable of maintaining and communicating the desired product information through all stages of the food supply chain (World Economic Forum, 2019). Food supply chains are becoming increasingly globalised, which poses challenges to guarantee symmetry,

51 trust and transparency for the shared product information. Due to their complex and interconnected nature, global food supply chains face difficulty in seeking to adopt a single, centralised, traceability system architecture especially if this is in the control of a third party,

54 that are monopolistic and opaque in nature. Further, such centralised traceability system 55 architecture is more vulnerable to collapse, since a single point of breakdown can cause the 56 whole system to crash (Tian, 2017; El Maouchi, Ersoy and Erkin, 2018). Distributed 
traceability system architectures have emerged as a response to these risks, making use of decentralised information capture and storage to deliver improved information symmetry, security, trust and transparency.

60

61

62

63

Although manual paper-based traceability systems are still commonly used, deployment of computerised FTSs is rising due to the rapid growth of information and communication technologies (ICTs) and the emergence of the Industry 4.0 (the so-called fourth industrial revolution) marked by the automation of production systems. The advancement of FTSs is clearly noticeable in the identification technology practices employed in food supply chains i.e., the extensive use of barcode technologies is being displaced by the use of radio frequency identification (RFID) which provides increased data capacity, reading speeds and accuracy (McCathie and Michael, 2005; Badia-Melis, Mishra and Ruiz-García, 2015). RFID can be supplemented with wireless sensors to support traceability-based product quality monitoring (Thakur and Forås, 2015; Alfian et al., 2020; Islam,Cullen \& Manning, 2021). These technologies when integrated with electronic product code information service (EPCIS) data standards, enable efficient product data transfer between supply chain partners (Mainetti et al., 2013) and through to customers. Moreover, Blockchain and smart contract technologies allow increased opportunity for transparency and tamperproof data recording in complex and globally distributed supply chains (Pearson et al., 2019).

Despite the availability of such revolutionary technologies, there are various barriers inherent within food systems which impede successful implementation of FTSs in individual companies or in sub-sections of supply chains (Bosona and Gebresenbet, 2013; Hardt, Flett and Howell, 2017; World Economic Forum, 2019). Barriers to the adoption of FTSs include: a lack of awareness and training on traceability and traceability technologies; a lack of standards development; resource deficiencies, including funding and capacity issues; inefficient data 
management; and finally, technology scaling issues (Islam and Cullen, 2021). The intensity of these barriers is influenced by the supply chain structure, its relationship dynamics, and the position of companies within the supply chain (Sterling et al., 2015). To harness the transformative power of breakthrough technologies and exploit the potential for FTSs to transform, food supply chains will require clear strategies and pathways to overcome the barriers identified above. This chapter considers exclusively the advancements in agri-food traceability systems and technologies, their implementation barriers and some potential improvement pathways to overcome these.

\section{Traceability drivers}

Implementation of FTSs is driven by several motivating factors, which are known as controlling forces (Norton et al., 2014) or traceability drivers in the literature. Traceability drivers differ across FTSs depending on what type of information the internal or the external stakeholders require. A set of five prominent traceability drivers are adopted from Islam and Cullen (2021) and are discussed below:

\subsection{Legislation and certification}

Traceability has been embedded as an indispensable requirement in the food legislation of several countries, including EU food law 178/2002; the US Bio-terrorism Act, the US Food Safety Modernization Act (FSMA); and Japan's Food Traceability Act (Bechini, Cimino, Marcelloni \& Tomasi, 2008; Charlebois, Sterling, Haratifar, \& Naing, 2014; Qian et al., 2020). Many of these food laws require the mandatory recording of the identification of immediate upstream suppliers and downstream customers, in what is known as the "one-up-one down" or “one step forward-one step back" traceability approach.

A key driver motivating many food companies to execute traceability is to meet the necessary legal requirements, so they can stay functional in markets. Some countries agree to abide by 
traceability regulations to gain access to export markets and introduce their own guidelines.

106 The traceability regulations developed by various parties (e.g., governments, regulators and

107 market actors) are often heavily influenced by the standards developed by the ISO

108 (International Organisation for Standardisation) such as ISO 22005(ISO, 2005) which defines

109 the functional requirements for the implementation of practical FTSs (Islam and Cullen, 2021).

110 The market driver for independently verifiable FTSs has led to the development of third party

111 private certification schemes (Norton et al., 2014).

\section{$112 \quad$ 2.2 Safety and quality}

113 Demonstrating compliance with food safety and quality standards emerges as a strong

114 motivating factor for implementing FTSs, driven by persistent shocks and costly disruptions to

115 food supply chains, including the European horse meat (scandal) substitution for beef, and more recently ethylene oxide recalls across Europe and COVID-19. These incidents impact the

117 perceived trustworthiness of food supply chains and lead to calls for increased transparency surrounding the safety and quality properties of food products (Aung and Chang, 2014). The interaction between traceability and transparency in food supply chains is gaining wider

120 interest (Baralla et al., 2020; Feng et al., 2020) especially where public health has to be ensured within complex food supply chains (Demestichas et al., 2020).

\section{$122 \quad 2.3$ Customer satisfaction}

123 FTSs both assure and create consumer confidence in the safety and quality of food (Qian et al.,

124 2020; Zhang et al., 2020), especially in a market where consumers have a high level of food 125 safety awareness (Rodriguez-Salvador and Dopico, 2020). Traceability protocols and the 126 designs of FTSs to reduce food safety risks are framed by these consumer preferences (FSA, 127 2002; Garaus and Treiblmaier, 2021). Indeed, Lam et al., (2020) argue that consumer trust in food safety is based on FTSs and information transparency. 


\subsection{Sustainability}

Traceability has become a strong basis for sustainability related credence claims that are difficult for consumers to ascertain, such as whether a food has been produced through sustainable production practices (Golan et al., 2004). Companies increasingly make use of traceability to validate sustainability claims and gain a competitive advantage from responsible environmental and social practices (Norton et al., 2014; Gallo et al., 2021; Islam and Cullen, 2021). For example, traceability helps companies to authenticate that the good animal welfare practices they claim to adhere to are in place, thereby leading to increased organisational reputation (Golan et al., 2004). With regard to fish supply chains in particular, illegal, unregulated and unreported (IUU) fishing can take place without concern for the environment or strict regulations and fishing quotas. Organisations can make use of FTSs to prevent IUU fish entering fish supply chains (Borit, \& Olsen, 2012). The Marine Stewardship Council (MSC) Standard for seafood sustainability requires batch level traceability, confirming that there is no presence of IUU fish from raw produce through to final consumer (Norton et al., 2014; Lin et al., 2020; Islam and Cullen, 2021). Thus, effective FTSs can underpin sustainability claims with regard to a given product.

\subsection{Value and efficiency}

Inventory management, effective product recall and product distribution are important motivators for companies implementing FTSs (Islam and Cullen, 2021). Retailers make extensive use of traceability for: efficient operational planning (Bourlakis and Bourlakis, 2006; Mishra et al., 2020), resource efficiency (Lin et al., 2020;) optimised shelf-life based distribution planning (Jedermann et al., 2014), prevention of animal theft (Smith et al., 2005) and minimising product recall cost (Opara, 2003).

\subsection{Summary}


153 Together, the five drivers identified above-legislation and certification; safety and quality;

154 customer satisfaction; sustainability; value and efficiency-underpin the case for improving 155 traceability in food supply chains and adopting new ICT technologies to deliver more efficient 156 FTSs.

\section{3. Food traceability in theory}

158 Numerous definitions of food traceability exist, provided by various organisations and 159 academics and detailed in multiple pieces of legislation (Islam and Cullen, 2021). The EU 160 General Food Law (2002) defines food traceability as: "the ability to trace and follow a food, 161 feed, food producing animal or substance intended to be, or expected to be incorporated into a 162 food or feed, through all stages of production, processing and distribution". According to the 163 ISO 9000 (2000), "traceability is the ability to trace the history, application or location of that which is under consideration". Olsen and Borit (2013) present traceability as: "the ability to access any or all information relating to that which is under consideration, throughout its entire life cycle, by means of recorded identifications”. Islam and Cullen (2021) most recently define food traceability as "an ability to access specific information about a food product that has been captured and integrated with the product's recorded identification throughout the supply 169 chain".

170 Moe (1998) provides further detail with the description of two main types of traceability in her 171 definition: chain traceability (or external traceability) is the "...ability to track a product batch

172 and its history through the whole, or part, of a production chain from harvest through transport, 173 storage, processing, distribution and sales', whereas internal traceability is the '...ability to 174 trace...in one of the steps in the chain". This means that traceability can operate at two levels 175 simultaneously, the supply chain level and the organisational level; and that for chain 
traceability to work effectively all discrete internal traceability activities must be

177 operationalised appropriately and synchronised with each other.

178 Internal traceability is enabled by the recording of product descriptors within the boundaries of a single FBO, while external traceability requires transmission of that information to other links

180 in the chain. Internal traceability is executed by grouping of raw materials and products into 181 batches or lots and assigning them discrete identifiers (Olsen and Borit, 2018; Islam and Cullen, 182 2021). The batches or lots, alternatively known as traceable resource units (TRU) (Moe, 1998), undergo several transformations that may encompass aggregation (e.g., mixing and combining) or disaggregation (e.g., splitting and portioning), for example, harvested fruit from multiple growers being pooled as one TRU, or conversely a livestock carcass being disaggregated to multiple cuts of meat being distinct TRU. As a TRU move internally within an FBO and/or through the food supply chain, the associated information needs to be communicated in tandem. In essence, information flows through the FTS from material origin to final product enabling traceability and visibility in supply chains. Thus, traceability as described here associates a product and its component parts; the organisations through which the product and

191 its component parts have been transferred; the modifications/transformations that have occurred at each point; and the characteristics of the data itself that in turn give information about the product and any aligned services.

\section{Food traceability system (FTS)}

The implementation of traceability in food supply chains, in practice, requires discrete FTSs. An FTS is the totality of data and operations that is capable of maintaining desired information

197 about the food product and its ingredients through all or part of the supply chain (World 198 Economic Forum, 2019). Although paper based manual recording is able to execute traceability in a one-up-one-down manner, it does not provide adequate transparency across the FSC. Transparency is defined as "the practice of being open and honest with customers in terms of 
food sourcing, ingredient lists, nutrition facts, allergen concerns, and ecological impact" (Food

Standards Agency, 2017). Lack of transparency results in a greater risk of food adulteration, counterfeiting and mislabelling (Manning, 2019a). Therefore, computerised traceability systems including pedigree, centralised and decentralised data management approaches have emerged which possess the potential to strengthen traceability leading to better transparency across food supply chains. The evolution of traceability systems, from manual to computerised systems and across centralised and distributed systems, is discussed below:

\subsection{Manual and computerised traceability systems}

Traceability systems have evolved from simple manual paper-based recordings to latest industry 4.0 technology-based information systems. Paper-based databases (Zhang et al., 2010) represent the simplest technique for data recording using paper trails, including the use of product registration books, faxes, paper forms, and postal letters. Paper based manual systems are adequate for implementing one-up-one-down based traceability systems i.e., to record the identification of immediate supplier and customer, and pedigree-based information system, such as the audit trail recording of a product's transformation and ownership as it passes along the supply chain (Alfian et al., 2017; Olsen, 2017). Paper-based traceability systems, involving manual transcription, require less expertise and less infrastructural cost to implement, however they are time consuming, less reliable, less suitable for further analysis and highly prone to human error or data loss (Frederiksen and Bremner, 2001).

220 Due to the weaknesses identified in paper-based traceability systems, computerised traceability systems, offering improved accuracy and reliability, have been extensively adopted across

222 various food supply chains (Regattieri, Gamberi and Manzini, 2007; Zhang et al., 2010; Feng et al., 2013). Computerised databases can be updated by a manual transcription or an automated transcription through various technologies, for example, barcodes, RFID and 
225 Wireless Sensor Networks (WSN). Computerised traceability systems for chain traceability across food supply chains can be implemented through database software with electronic data

227 interchange (EDI) capacity, centralised cloud-based information systems or decentralised Blockchain technology. Although they require increased infrastructural costs, training and expertise, computerised traceability systems provide improved information storage and retrieval, reliability, transparency, data standardization, security, and ease of subsequent analysis and interrogation.

\subsection{Central and distributed traceability system}

Traceability systems can be categorised by the degree of independence of the databases used throughout the supply chain i.e., whether the traceability system is based on centralised or distributed information systems (Hugoson, 2007; Tian, 2017). An important distinction between centralised and decentralised information systems is the data location used in individual FBOs for recording and transmitting traceability data, which can be described as totally distributed, compressed and distributed, or centralised (Gandino et al., 2009). In the totally distributed approach, data are stored directly as detail such as written words or RFID labels directly on the product or packaging, for example, the use of ear tags attached to the animals containing detailed animal history when the animal is moved from one food supply chain link to the next (Feng et al., 2013). In the compressed and distributed approach data are stored in a compressed form (e.g., short code) which is linked to a reference database, for example, a barcode, containing product identification, links a product to a reference database which detail product operation information (McCathie and Michael, 2005). However, all traceability data can also be stored in a centralised database and its link can be attached to the given item, say, in the form of a QR code. Such information system is commonly used in retail store product tagging where the tag code links back to a centralised database containing detailed product information (Tarjan et al., 2014). 
250 Another distinction between centralisation and decentralisation is observed through the choice to store data in a centralised or decentralised information system that influences the way traceability data is integrated or shared across multiple FBOs. In the centralised architecture, a central database owned by an external third party is responsible for all traceability data (Bechini et al., 2005). This architecture requires the responsible FBO to provide to a third party the information related to that activity (Huang, Zhou and Liu, 2019). This information must allow the central database to, at a minimum, record the lot transformation, i.e., the association between the input lot(s) and the output lot(s) (Bechini et al., 2005). This approach, is however, susceptible to single node (central database) attack and data tampering with the loss of data confidentiality leading to decreased data security (Huang, Zhou and Liu, 2019).

In the decentralised approach, the FBO responsible for an activity records the transformation relationships between the associated input and output lots. The FBO then communicates the global identifier of their produced lot through a preferred communication channel (e.g., EDI, product tag or accompanied documents) to the distributor, which, then provides to associate the input with the global identifier of the subsequent output (Bechini et al., 2005). This approach may suffer from lack of standardisation, information tampering and non-transparency (Tian, 2017).

Therefore, increased attention has recently been focused on an alternative decentralised data recording approach known as Blockchain: a chronological chain of blocks with each block added to the chain after storing information regarding a distinct network activity (e.g., transaction, supply chain operation) with an identifiable timestamp (Tian, 2017). All users, considered as nodes in the network, are, with suitable permissions, able to see the recorded

272 data in the chain of blocks at any time, but no one can change it, due to cryptographic protection

273 (Salah et al., 2019). Being an immutable history of network activities, Blockchain provides 
means to share traceability data among all nodes (i.e., supply chain actors) in the system. Using

275 a Blockchain-based information system removes the risk of using a centralised third-party

276 traceability database, while providing transparency, authenticity, security and tamper proofing

277 of the shared traceability information for all nodes in the system. More detail about Blockchain

278 technology is provided in the next section.

\section{5. Traceability technologies}

280 The so-called fourth Industrial Revolution (or Industry 4.0) is characterised by the ongoing automation of traditional manufacturing and industrial practices using modern smart technologies that enable large-scale machine-to-machine communication (M2M) and the Internet of Things (IoT) providing improved communication, self-monitoring and diagnosis of issues without the need for human intervention. The emergence of the Industry 4.0 revolution can also be seen in food traceability systems where automatic identification (auto-ID) technologies, sensors and communication technologies are integrated for managing food product information throughout food supply chains (Chen, 2017). The emergence of these technologies in food traceability systems is shown in Table 1 and discussed below:

\subsection{Barcode}

290 The barcode emerged in the early 1970s and is now considered to be the first auto-ID technology. It has been widely used in many different supply chain management practices (McCathie and Michael, 2005; Tu et al., 2020). A barcode is operationalised as a symbology that encodes information in the form of either one-dimensional (1D) parallel lines (i.e. bars and spaces) or a two-dimensional (2D) matrices of dots (Palmer, 1989; Tu et al., 2020). Barcodes are printed on various types of materials which can be read by special dedicated optical barcode scanners, handheld personal digital assistants (PDA) or smartphones using special application (McCathie and Michael, 2005; Reischach et al., 2011; Tu et al., 2020). When the right 
infrastructure, software and hardware are in place, the automation provided by a barcode system greatly simplifies information collection, processing and tracking for the users (McCathie and Michael, 2005).

301 Over the years, many different kinds of 1D and 2D bar code symbologies have been developed, 302 each with its own intended industrial purpose and characteristics, for example, Code 39, Code 303 128, Data Matrix and QR Code (Musa, Gunasekaran and Yusuf, 2014; Tu et al., 2020). Barcode scanning is considered a reliable form of production identification, owing to its higher accuracy rates and high speeds in comparison to manual data collection (McCathie and Michael, 2005). However, accuracy attained through barcode technology can be compromised by the technology's requirement for using humans to perform scans, leading to potential mistakes (Singer, 2003). Barcode readers require direct 'line-of-sight' for barcode scanning and closerange reading of item one at a time, often making the data acquisition difficult and time consuming. This 'line-of-sight' property leads to more noticeable performance downturn for scanners in harsh environments, such as fog, dirt and rain (McCathie \& Michael, 2005). Barcodes are also more vulnerable to security loss, with the cloning or modification of 1D

313 barcode tag information being much easier than for say RFID whose information is not visible 314 to outside.

\section{$315 \quad 5.2$ RFID}

316 RFID is another auto-ID technology that uses radio frequency signals to identify products and

317 consists of three necessary hardware components: an electronic tag or transponder, a reader or 318 interrogator, and a supervising computer (Tan and Koo, 2014). The primary benefits of RFID, 319 over barcode technology, are: a large tag code offering item-level unique identification; rapid 320 data acquisition simultaneously from multiple tags which enables automatic TRU reading in the production line; non-line-of-sight and no contact scanning which allows tags to still be 
readable even when encapsulated; security features, such as deep encryption and password

323 protection, to mitigate against security breaches or counterfeiting (McCathie and Michael,

324 2005).

325 RFID technology is employed in a number of different systems which vary by the reader 326 transmission frequency, reading range, reading speed, operating environment and cost

327 (RFID4U). The four basic frequency ranges are: LF (low frequency 125/134 KHz), HF (high frequency 13.56 MHz), UHF (ultra-high frequency 860-960 MHz) and microwave frequency (2.45 GHz). RFIDs can also be categorised into: passive RFID, semi-passive RFID and active RFID (Tu, Zhou, \& Piramuthu, 2020). Passive RFID tags do not possess their own power source and therefore can only send information when energised by encountering with an RFID reader. This results in tags which are smaller, lightweight and less expensive, however, the lack of power supply limits the integration of some wireless sensors which require reliable continuous power to operate. Semi-passive RFID and active RFID tags, with on-tag batteries, provide longer reading ranges, higher data transmission rates and compatibility with a wide range of sensors for recording product physical and environmental data. The on-board power supply and additional functionalities increase the weight, size and cost of these RFID tags, in comparison to passive RFID transponders. RFID tags are also classified by their tag memory programmability, which include: Read-Only; Write Once, Read Many (WORM); and ReadWrite.

\subsection{NFC}

342 Near Field Communication (NFC) technology also uses radio frequency for data transmission 343 and operates on the same frequency as HF RFID (13.56 MHz) supporting high data transfer 344 rates of 106, 212, 424 or $848 \mathrm{Kbit} / \mathrm{s}$ (Mainetti et al., 2013). NFC technology is capable of twoway communications, including data transfer between two NFC mobiles, and one-way 
communication, with NFC devices and NFC tags, in a similar arrangement to passive RFID.

347 NFC tags do not require a dedicated reader for data transfer; they can be read by any smartphone that has NFC capability. NFC compatible phones are designed to send out short magnetic field pulses at the designated radio frequency, inducing an electric current in the tag's circuit and relaying the information to the phone (Trafton, 2014). Unlike RFID, only one NFC tag can be read at a time and they are capable of read-write programmability.

\subsection{WSN}

WSN is a network of spatially dispersed and dedicated sensors that collect sensing data of various physical or environmental conditions and communicates them with a base station or central node, from where data is then transmitted to a database server, using an IoT gateway and mobile networks e.g., General Packet Radio Service (GPRS) (Costa et al., 2013; Aung and Chang, 2014). The WSN is built having between a few to several hundred "nodes", where each node, consisting of a radio transceiver with an antenna connection, a microcontroller, memory capacity and energy source, connects to one or several sensors through an electronic circuit.

Although WSN nodes have limited processing capability and memory (Hammervoll et al., 2012), their ability to communicate with each other in various network topologies offsets the impact of missing communication from any single node to the base station, and hence reduces error rate (Costa et al., 2013). This is the main advantage of WSN over RFID systems as RFID devices do not possess cooperative capabilities. WSNs have much longer reading ranges than RFID, due to their ability to relay information from node to node, but are not suitable for identification purposes owing to their inability to transmit product identification (Ruiz-Garcia et al., 2009; Aung and Chang, 2014). A further advantage for the WSN system is the feasibility of installation in places where cabling is impossible, such as within the cargo for monitoring physical and environmental conditions of perishable food (Ruiz-Garcia et al., 2009). 
370 At a reasonable cost and power consumption, WSN can provide real-time information on

371 various parameters, such as the temperature, humidity and vibration experienced by perishable

372 food in transit (Hammervoll et al., 2012). Power consumption can be reduced by placing the 373 sensors into sleep mode after each successful data emission, and only waking up the sensor

374 when required, at regular intervals (Aung and Chang, 2014). Low temperature is known to 375 have a negative effect on the battery life of sensors (Ruiz-Garcia et al., 2009). The ZigBee 376 communication protocol has been proposed to prolong the battery life of sensors. ZigBee is 377 built on the IEEE 802.15.4 standard and supports various network topologies for wireless 378 sensor networks with low energy consumption and low data transmission rates (Óskarsdóttir 379 and Oddsson, 2019).

\section{$380 \quad 5.5$ EPCglobal standards}

381 EPCglobal is a worldwide association of supply chain partners providing open standards for 382 Electronic Product Code (EPC) and Electronic Product Code Information System (EPCIS). EPCglobal enables effective communication through recording and exchange of product data as products moves through supply chain actors and across country borders (Asher et al., 2007). EPC is unique, serialised identification code format for any kind of product that can be encoded from familiar identifiers, such as Global Trade Item Number (GTIN) and Serialised Shipping Container Code (SSCC). EPCIS is a universal data model for representing the location and state of product as it moves across organisational boundaries, while providing a means for communication between these organisations regardless of the technology suppliers.

The main components of an EPCIS data model include EPC, Event Time, Business Step, Disposition, Read Point, Business Location, and Business Transaction. However, it is often extended in practice to also include Expiration Date, Batch Number, and Temperature. The EPCIS standard is data carrier neutral and can be used to describe data captured from various 
technologies including RFID tags, barcodes and other data carriers (Asher et al., 2007). The

EPCIS databases of different supply chain participants, being connected via local networks or

internet, provide a lineage of products movement which is accessible by authorised parties.

The accessibility is enabled by deploying a discovery mechanism (e.g., object naming service or ONS) that takes an EPC as an input and replies back the address (in the form of a Uniform

Resource Locator, or URL) of an EPCIS repository implemented by the supply chain actor corresponding to the EPC in question (Musa, Gunasekaran and Yusuf, 2014).

The EPCIS framework for an industry is extensible, in that it allows new industry requirements to co-exist alongside the core components while still providing interoperability (Asher et al., 2007). There are no technology implementation standards for EPCIS and there are many solution providers who provide EPCIS compliant technology solutions, using firewalls, encoding, and other safe measures to guarantee the security of the transmitted information (Musa et al., 2014).

\subsection{Cloud computing}

408 Cloud computing is the provision of dynamically scalable and often virtualised resources, for example, data storage or software application as a service (SAAS) over the internet (Patil et al., 2012). In practice, cloud computing often refers to internet-based development and use of computing technology. Clouds may be limited to a single organisation, such as enterprise clouds managed by the enterprise IT department, or can be available to multiple organisations, for example public clouds managed by a third party (Wang et al., 2012). The cloud computing

414 architecture comprises three layers: resource, platform and application. The resource layer 415 consists of various hardware used for identification and communication, including personal 416 digital assistants (PDAs), computers, and middleware, which are owned by supply chain operators. Middleware can be described as a software that is the glue or the hidden transition 
418 layer bridging the gaps between applications, tools, and databases in order to provide unified 419 services to users (Microsoft Azure, nd). The platform layer includes components such as web 420 servers, application servers, and enterprise service buses, and serves users by providing

421 functionality such as information access. The application layer is the main layer consisting of 422 the applications to serve the users e.g., various internet-based software. Cloud computing 423 provides several advantages for FTSs, including increased scalability, agility, availability, 424 multi-sharing, services in a pay-per-use mode, automated backup, and support for service 425 oriented applications (Wang et al., 2012).

426 At present, the mainstream traceability systems for food products are often maintained and 427 governed by the government or a leading enterprise by using a centralised cloud-based 428 information system, which participants with accessibility permission can use to input their 429 respective traceability information or to simply access to visualise the data. Such an approach 430 facilitates a common standard database for users, reducing the need for data standardisation 431 efforts by individual companies. However, cloud-based systems may suffer from information 432 tampering, label cloning, product counterfeiting, illegal product trading, accountability 433 difficulty, loss of confidentiality and malicious attack of the central database (Huang et al., 434 2019; Manning, 2019b).

\section{$435 \quad 5.7$ Blockchain}

436 Unlike cloud databases managed by central authorities, Blockchain technology provides a 437 distributed database that is participated in, and maintained by, all nodes in a peer-to-peer (P2P) 438 network, or all actors in a food supply chain network (Li et al., 2020). The Blockchain is an 439 immutable, distributed ledger. In practice, this is an ever-growing list of chronologically linked 440 records, called blocks, which store transaction and asset data across many computers throughout the supply chain network. Each block also contains a cryptographic hash of the 
442 previous block and a timestamp, so that any involved block in a given connection cannot be 443 altered retroactively, without the associated alteration of all subsequent blocks (Wang et al., 444 2018). Due to its tamperproof, secure and traceable nature, Blockchains can be deployed 445 effectively in implementing FTSs (Salah et al., 2019). Blockchain is often implemented by 446 deploying a smart contract: a computer programme which defines the protocols of a business contract that governs and controls all interactions and transactions among all the participants involved within a P2P network or supply chain, without the need of a centralised third party (Salah et al., 2019). Blockchain-based FTSs mainly record and merge the product traceability data and transaction information between FSC parties. Each company in the network also maintains their own individual internal traceability database, often using decentralised file systems, which allows linking of internal traceability data with external traceability data in the block and the verification of traceability data integrity (Salah et al., 2019; Li et al., 2020).

454 Product traceability data is typically stored in decentralised file systems and uploaded to the smart contract platform, which is then broadcast over the whole Blockchain network to ensure authenticity (Huang et al., 2019). Data are verified by the consensus mechanism by other nodes 457 in the Blockchain network before being stored. Trade requests are first verified, before the product ownership is transferred, and any transaction information are packed into a block. Each block is hashed and linked to the next block, making it a secure chain of immutable and tamperproof records of all transactions, spread across all nodes in the network. In this distributed information system, smart contracts ensure the standardisation of the recorded traceability data

462 (Li et al., 2020). Ethereum, a programmable smart contract platform is popularly used for 463 implementing Blockchain-based information systems among supply chains.

464 The advantages of Blockchain based traceability systems includes decentralisation, non465 tampering protection, data verification, privacy, distributed data storage, transparency and 
466 increased trust (Abeyratne and Monfared, 2016; Tian, 2017; Behnke and Janssen, 2020).

467 However, the technology still needs some improvement as it suffers from various

468 disadvantages: Blockchain network can become bulky with time if an unrestricted number of

469 users join, slowing down the addition of new data addition(Behnke and Janssen, 2020); some

470 Blockchain designs do not have any functionality to protect sensitive information from certain

471 users (Feng et al., 2019); Blockchain software written with poorly developed codes is

472 vulnerable to hacking (DeVries, 2016); Blockchain traceability systems can incur high

473 implementation and electricity consumption costs (Li et al., 2019); there is high requirements

474 for training(Behnke and Janssen, 2020); and the technology is not profitably scalable across

475 small supply chains (World Economic Forum, 2019). 


\begin{tabular}{|c|c|c|c|}
\hline Technologies & Technology type & Advantage & Disadvantage \\
\hline Bar code & $\begin{array}{l}\text { Identification } \\
\text { technology }\end{array}$ & $\begin{array}{l}\text { - Cheaper compared to RFID and manual } \\
\text { paper document. } \\
\text { - Easy to use. } \\
\text { - More reliability, high speed and accuracy } \\
\text { than manual methods }\end{array}$ & $\begin{array}{l}\text { - Line-of-sight data reading } \\
\text { - Risk of optical damage } \\
\text { - Less accuracy compared to RFID. } \\
\text { - Time consuming for one-by-one tag data reading } \\
\text { - Shorter reading range than RFID } \\
\text { - More vulnerable to security loss in comparison to RFID }\end{array}$ \\
\hline $\begin{array}{l}\text { Radio } \\
\text { frequency } \\
\text { Identification } \\
\text { (RFID) }\end{array}$ & $\begin{array}{l}\text { Identification } \\
\text { technology }\end{array}$ & $\begin{array}{l}\text { - Line of sight is not required } \\
\text { - Longer reading range, high speed reading } \\
\text { and high accuracy } \\
\text { - Store larger amount of data } \\
\text { - Tag durability } \\
\text { - Multiple tag reading at a time increases } \\
\text { automation } \\
\text { - Higher data security than barcode }\end{array}$ & $\begin{array}{l}\text { - Not profitable for low value items. } \\
\text { - Cost of infrastructure is high } \\
\text { - High expertise or training required } \\
\text { - Tag collision may occur }\end{array}$ \\
\hline $\begin{array}{l}\text { Near Field } \\
\text { Communication } \\
\text { (NFC) }\end{array}$ & $\begin{array}{l}\text { Identification } \\
\text { technology }\end{array}$ & $\begin{array}{l}\text { - Line-of-sight data reading is not required } \\
\text { - Carries more data than bar code } \\
\text { - Wireless data transfer } \\
\text { - No need of dedicated reader as mobile } \\
\text { phones can be used } \\
\text { - Offers read-write programmability for } \\
\text { tag data }\end{array}$ & $\begin{array}{l}\text { - Not profitable for low value items. } \\
\text { - High expertise or training required } \\
\text { - Slow reading rate than RFID as multiple tag reading is not } \\
\text { possible } \\
\text { - Technology is not matured yet. }\end{array}$ \\
\hline $\begin{array}{l}\text { Wireless } \\
\text { Sensor } \\
\text { Network } \\
\text { (WSN) }\end{array}$ & $\begin{array}{l}\text { Physical and } \\
\text { environmental } \\
\text { property } \\
\text { recording } \\
\text { technology }\end{array}$ & $\begin{array}{l}\text { - Wireless product physical and } \\
\text { environmental data collection } \\
\text { - Higher reading range than RFID } \\
\text { - Cooperation among multiple data } \\
\text { collection nodes }\end{array}$ & $\begin{array}{l}\text { - Cannot provide product identification } \\
\text { - Expensive for low value item } \\
\text { - High expertise or training required }\end{array}$ \\
\hline EPCglobal & $\begin{array}{l}\text { Identification } \\
\text { and } \\
\text { communication } \\
\text { standards }\end{array}$ & $\begin{array}{l}\text { - Standards for product identification } \\
\text { code and database } \\
\text { - Interoperability in external traceability } \\
\text { information communication } \\
\text { - Easily scalable }\end{array}$ & $\begin{array}{l}\text { - No technology standards are defined } \\
\text { - Difficult to adopt for manual traceability system } \\
\text { - No standards for sensor data }\end{array}$ \\
\hline
\end{tabular}




\begin{tabular}{|c|c|c|c|}
\hline $\begin{array}{l}\text { Cloud } \\
\text { computing }\end{array}$ & $\begin{array}{l}\text { Communication } \\
\text { technology }\end{array}$ & $\begin{array}{l}\text { - High scalability } \\
\text { - Agility and high availability } \\
\text { - Multi-sharing of databases } \\
\text { - Services in the pay-per-use mode } \\
\text { - Automated backup of traceability } \\
\text { database }\end{array}$ & $\begin{array}{l}\text { - Cannot provide data authentication } \\
\text { - Vulnerable to single node attack } \\
\text { - May suffer from information tampering and label cloning } \\
\text { - Not possible to delegate accountability for data } \\
\text { - May encounter Loss of confidentiality and malicious attack }\end{array}$ \\
\hline Blockchain & $\begin{array}{l}\text { Communication } \\
\text { technology }\end{array}$ & $\begin{array}{l}\text { - Provides transparency, trust and } \\
\text { authenticity } \\
\text { - Does not require centralised third party } \\
\text { - Eliminates the requirements for large } \\
\text { data sharing on product tag }\end{array}$ & $\begin{array}{l}\text { - Slow information recording } \\
\text { - Susceptible to system hacking } \\
\text { - Expensive for low value items and small holders } \\
\text { - } \text { Difficulty with technology scalability } \\
\text { - High expertise or training required }\end{array}$ \\
\hline
\end{tabular}




\section{Barriers in implementation of effective FTS}

478 Despite the enormous potential of emerging technologies to improve traceability, various 479 barriers exist that hinder their implementation in FTSs. Some of these barriers are discussed 480 below:

\section{$481 \quad 6.1$ Lack of awareness}

482 There is a lack of understanding of the theoretical traceability concepts, and how traceability differs from other similar concepts such as chain of custody (Olsen, 2017). For example, a

484 United Kingdom (UK) survey of small and medium sized food and drink industries shows that only $25 \%$ of participant companies align the term "traceability" with information and product logistics that leads to reduced effectiveness of their traceability systems and implementation

487 (Mattevi and Jones, 2016). In addition, there appears to be widespread resistance to the implementation and use of new technologies, with many FBOs still relying on manual traceability systems. Many FBOs are not aware of all the potential benefits of implementing improved traceability, seeing only the additional upfront capital investment and legal requirements. Instead, they persist with paper-based one-up-one-down traceability systems,

492 which are limited only to identification of suppliers and customers (Asioli, Boecker and 493 Canavari, 2014).

\section{$494 \quad 6.2$ Resource deficiencies}

495 A barrier to improved practical food traceability results from resource deficiencies and a lack 496 of funding, as traceability implementation is expensive and complicated (Bosona and

497 Gebresenbet, 2013). The allocation of costs and benefits among food supply chain partners, 498 during traceability implementation, requires considerable effort and results in initial resistance against implementation. The introduction of new FTSs also requires increased administrative 
work, training and capacity building, especially when companies are implementing traceability systems for the first time (Bosona and Gebresenbet, 2013).

502

503

504

505

506

507

508

509

510

511

512

513

514

515

516

517

518

519

520

521

522

523

\subsection{Inefficient data management}

Inefficient information flow in FTSs has been revealed, in practice, by recurrent food crises (Badia-Melis, Mishra and Ruiz-García, 2015). Inefficient information flow is associated with poor traceability data management in individual FBOs' internal FTSs (Duan et al., 2017). Information loss for an FBO occurs when the product and its operational or quality information are not systematically recorded or linked at the key information collection points (Karlsen et al., 2011; Zhang and Bhatt, 2014). This can happen as a result of failure in TRU identification and transformation recording, incompetent recording techniques, absence of industry specific standard data lists, and simply human error (Bertolini et al., 2006; Karlsen et al., 2011; Zhang and Bhatt, 2014; Karlsen and Olsen, 2016).

\subsection{Lack of standards}

Various food supply chain operators generate an increasing amount of traceability data using various technologies, which is essential for effective traceability. For example, a farm may use simple paper trails for data recording, while processors are equipped with enterprise resource planning (ERP) software. However, the prevalence of heterogeneous data sources, means a traceability system may face significant interoperability challenge and data integration issues (Bougdira et al., 2019). This issue is amplified by the lack of a widely adopted standard for how FBOs record and transmit data for traceability, which in turn, hinders adoption of novel communication technologies (e.g., Blockchain) (World Economic Forum, 2019).

\subsection{Technology cost and scaling issues}

Cost is often considered to be the main constraint preventing the more widespread use of ICT and Industry 4.0 technologies (e.g., RFID, WSN, Blockchain), especially in the case of low 
value items procured from smallholders. Some technologies (e.g., Blockchain) do not appear

525 profitable for small scale food supply chains due to its high set-up cost (World Economic

526 Forum, 2019). However, the upfront costs of implementing improved traceability systems

527 using novel technologies is frequently considered in isolation, as an additional cost, without

528 weighing this against the potential cost reduction through ensuring the safety, quality and

529 authenticity of food products. This is because the benefits of improved traceability and the

530 reduction in risk to the food supply, are challenging to price. There is an urgent need for

531 scientists and practitioners to co-develop new tools to assess the risks and potential costs of not

532 implementing more advanced traceability systems.

\section{7. Improvement pathways}

534 To adopt new technologies and achieve desired outcomes, new pathways need to be created

535 which drive improved traceability. Some improvement pathways and policy interventions are 536 outlined below:

- Multi-stakeholder collaborations combined with financing and policy incentives need to be

538 developed that can support FBOs in adopting emerging technologies that would otherwise

539 necessitate high capital investments and operational costs beyond the reach of such $540 \quad$ organisations (World Economic Forum, 2019).

541 - Ongoing technological development needs to be supported through policy intervention to

542 drive down the costs of adopting more advanced traceability solutions. An example can be

543 the "Contract for Difference (CfD)" of the UK government to reduce prices of renewable

544 electricity technologies (Evans, 2017).

545 - Technology and data format standards are available for national animal traceability in many 546 countries (Charlebois et al., 2014). Similar standards from GS1 can be embedded in the 
547 legal requirements for traceability of food which are more vulnerable to fraud e.g., olive $548 \quad$ oil and seafood (Mermelstein, 2015).

549

550

551

552

553

554

555

556

557

558

559

560

561

562

563

564

565

- Sector specific clear, consistent and globally harmonised standards should continue to be developed such as ISO 12875:2011 and 12877:2011 for captured and farmed finfish (Olsen, 2017)

- New tools and frameworks for assessing the risks and potential costs of food quality loss and safety breaches, against the investment costs in advanced traceability systems are required to be developed for encouraging more advanced FTSs.

\section{Where to look for further information}

The following articles provide a good overview of the subject discussed in this chapter:

- Islam, S., \& Cullen, J. M. (2021). 'Food Traceability: A Generic Theoretical Framework', Food Control, 123, 107848.

- Badia-Melis, R., Mishra, P. and Ruiz-García, L. (2015) 'Food traceability: New trends and recent advances. A review', Food Control, 57, pp. 393-401.

- Bosona, T., \& Gebresenbet, G. (2013). 'Food traceability as an integral part of logistics management in food and agricultural supply chain'. Food Control, 33(1), pp. 32-48.

- Lees, M. ed., 2003. Food authenticity and traceability. Elsevier.

- World Economic Forum (2019) Innovation with a purpose: Improving traceability in food value chains through technology innovations. 
567 Abeyratne, S. A. and Monfared, R. P. "Blockchain ready manufacturing supply chain using

568 distributed ledger." International Journal of Research in Engineering and Technology 5, no. 9 569 (2016): 1-10.

570 Alfian, G. et al. (2017) 'Integration of RFID, wireless sensor networks, and data mining in an 571 e-pedigree food traceability system', Journal of Food Engineering, 212, pp. 65-75. doi: 572 10.1016/j.jfoodeng.2017.05.008.

573 Alfian, G. et al. (2020) 'Improving efficiency of RFID-based traceability system for perishable 574 food by utilizing IoT sensors and machine learning model', Food Control, 110, p. 107016. doi: 575 https://doi.org/10.1016/j.foodcont.2019.107016.

576 Asher, C. et al. (2007) EPCIS (Electronic Product Code Information Service) Frequently Asked 577 Questions, EPCglobal.

578 Asioli, D., Boecker, A. and Canavari, M. (2014) 'On the linkages between traceability levels 579 and expected and actual traceability costs and benefits in the Italian fishery supply chain', Food 580 Control. Elsevier, 46, pp. 10-17.

581 Aung, M. M. and Chang, Y. S. (2014) 'Traceability in a food supply chain: Safety and quality 582 perspectives', Food Control. Elsevier Ltd, 39(1), pp. 172-184. doi: 583 10.1016/j.foodcont.2013.11.007.

584 Azuara, G., Tornos, J. L. and Salazar, J. L. (2012) 'Improving RFID traceability systems with 585 verifiable quality', Industrial Management \& Data Systems. Emerald Group Publishing 586 Limited.

587 Badia-Melis, R., Mishra, P. and Ruiz-García, L. (2015) 'Food traceability: New trends and 588 recent advances. A review', Food Control, 57, pp. 393-401. doi: 589 https://doi.org/10.1016/j.foodcont.2015.05.005.

590 Bai, X. et al. (2018) 'Shiga toxin-producing Escherichia coli infection in Jönköping county, 591 Sweden: occurrence and molecular characteristics in correlation with clinical symptoms and 592 duration of stx shedding', Frontiers in cellular and infection microbiology. Frontiers, 8, p. 125.

593 Baralla, G., Pinna, A., Tonelli, R., Marchesi, M., \& Ibba, S. (2021). Ensuring transparency and 594 traceability of food local products: A blockchain application to a Smart Tourism 595 Region. Concurrency and Computation: Practice and Experience, 33(1), e5857.

596 Bechini, A. et al. (2005) 'A general framework for food traceability', in 2005 Symposium on 597 Applications and the Internet Workshops (SAINT 2005 Workshops). IEEE, pp. 366-369.

598 Behnke, K. and Janssen, M. (2020) 'Boundary conditions for traceability in food supply chains 
599

600

601

602

603

604

605

606

607

608

609

610

611

612

613

614 Charlebois, S. et al. (2014) 'Comparison of global food traceability regulations and 615 requirements', Comprehensive reviews in food science and food safety. Wiley Online Library, 616 13(5), pp. 1104-1123.

617 Chen, R. Y. (2017) 'An intelligent value stream-based approach to collaboration of food 618 traceability cyber physical system by fog computing', Food Control. Elsevier Ltd, 71, pp. 124619 136. doi: 10.1016/j.foodcont.2016.06.042.

620 Costa, C. et al. (2013) 'A review on agri-food supply chain traceability by means of RFID 621 technology’, Food and bioprocess technology. Springer, 6(2), pp. 353-366.

622 Demestichas, K., Peppes, N., Alexakis, T., \& Adamopoulou, E. (2020). Blockchain in 623 Agriculture Traceability Systems: A Review. Applied Sciences, 10(12), 4113.

624 DeVries, P. D. (2016). An analysis of cryptocurrency, bitcoin, and the future. International 625 Journal of Business Management and Commerce, 1(2), 1-9.

626 Dong, K. T. P. et al. (2019) 'Pressure-State-Response of traceability implementation in 627 seafood-exporting countries: evidence from Vietnamese shrimp products', Aquaculture 628 international. Springer, 27(5), pp. 1209-1229.

629 Duan, Y. et al. (2017) 'A framework for the successful implementation of food traceability 630 systems in China', Information Society, pp. 226-242. doi: 10.1080/01972243.2017.1318325. 
631 EU (2002) 'Regulation (EC) No 178/2002 of the European Parliament and of the Council of

63228 January 2002 laying down the general principles and requirements of food law, establishing 633 the European Food Safety Authority and laying down procedures in matters of food saf', 634 Official Journal of the European Communities, 31, pp. 1-24.

635 Evans, S. (2017) Analysis: UK auction reveals offshore wind cheaper than new gas, 636 CarbonBrief. Available at: https://www.carbonbrief.org/analysis-uk-auction-offshore-wind637 cheaper-than-new-gas (Accessed: 21 January 2021).

638 FAO (2019) The future of food safety. First FAO/WHO/AU International Food Safety 639 Conference Addis, 12-13 February,2019. Available at: 640 http://www.fao.org/3/ca4289en/CA4289EN.pdf.

641 Feng, H., Wang, X., Duan, Y., Zhang, J., \& Zhang, X. (2020). Applying blockchain technology 642 to improve agri-food traceability: A review of development methods, benefits and 643 challenges. Journal of cleaner production, 260, 121031.

644 Feng, Q., He, D., Zeadally, S., Khan, M. K., \& Kumar, N. (2019). A survey on privacy 645 protection in blockchain system. Journal of Network and Computer Applications, 126, 45-58.

646 Feng, J. et al. (2013) 'Development and evaluation on a RFID-based traceability system for 647 cattle/beef quality safety in China', Food Control. Elsevier Ltd, 31(2), pp. 314-325. doi: $648 \quad 10.1016 /$ j.foodcont.2012.10.016.

649 Food Standards Agency (2017) Food Standards Agency Transparency: Understanding public 650 views and priorities Report.

651 Frederiksen, M. T. and Bremner, A. (2001) 'Fresh fish distribution chains: An analysis of three 652 Danish and three Australian chains', Food Australia. Australian Institute of Food Science and 653 Technology Inc., 54(4), pp. 117-123.

654 FSA (2002) 'Traceability in the Food Chain. A preliminary study'. Food Chain Strategy 655 Division, Food Standards Agency London.

656 Gallo, A., Accorsi, R., Goh, A., Hsiao, H., \& Manzini, R. (2021). A traceability-support system 657 to control safety and sustainability indicators in food distribution. Food Control, 124, 107866.

658 Gandino, F. et al. (2009) 'On improving automation by integrating RFID in the traceability 659 management of the agri-food sector', IEEE Transactions on Industrial Electronics. IEEE, 660 56(7), pp. 2357-2365.

661 Garaus, M., \& Treiblmaier, H. (2021). The influence of blockchain-based food traceability on 662 retailer choice: The mediating role of trust. Food Control, 108082.

663 Golan, E. et al. (2004) Traceability in the U.S. Food Supply: Economic Theory and Industry 
664 Studies, Traceability in the U.S. Food Supply: Economic Theory and Industry Studies. doi: 665 10.1001/jama.1971.03190220052018.

666 Hammervoll, T. et al. (2012) 'Criteria for temperature alerts in cod supply chains', 667 International Journal of Physical Distribution \& Logistics Management. Emerald Group 668 Publishing Limited.

669 Hardt, M. J., Flett, K. and Howell, C. J. (2017) 'Current barriers to large-scale interoperability 670 of traceability technology in the seafood sector', Journal of food science. Wiley Online Library, 671 82(S1), pp. A3-A12.

672 Huang, H., Zhou, X. and Liu, J. (2019) 'Food supply chain traceability scheme based on 673 Blockchain and EPC technology', in International Conference on Smart Blockchain. Springer, 674 pp. 32-42.

675 Hugoson, M.-Å. (2007) 'Centralized versus Decentralized Information Systems', in IFIP 676 Conference on History of Nordic Computing. Springer, pp. 106-115.

677 Islam, S. and Cullen, J. M. (2021) 'Food Traceability: A Generic Theoretical Framework', 678 Food Control. Elsevier, 123, p. 107848.

679 Islam, S., Cullen, J. M., \& Manning, L. (2021). Visualising food traceability systems: A novel 680 system architecture for mapping material and information flow. Trends in Food Science \& 681 Technology (In press). https://doi.org/https://doi.org/10.1016/j.tifs.2021.04.020

682 ISO (2000) ISO/TC 176/SC 1 9000:2000, Quality management systems- Fundamentals and 683 vocabulary, 2000.

684 ISO (2005) ISO/TC 176/SC 1 22005:2005, Traceability in the feed and food chain - General 685 principles and basic requirements for system design and implementation (2005).

686

687

688

689

690

691

692

693

694

695

696
Jedermann, R. et al. (2014) 'Reducing food losses by intelligent food logistics', Philosophical Transactions of the Royal Society A: Mathematical, Physical and Engineering Sciences. doi: 10.1098/rsta.2013.0302.

Karlsen, K. M., Donnelly, K. A. M. and Olsen, P. (2011) 'Granularity and its importance for traceability in a farmed salmon supply chain', Journal of Food Engineering. Elsevier Ltd, 102(1), pp. 1-8. doi: 10.1016/j.jfoodeng.2010.06.022.

Karlsen, K. M. and Olsen, P. (2016) Problems and Implementation Hurdles in Food Traceability, Advances in Food Traceability Techniques and Technologies: Improving Quality Throughout the Food Chain. Elsevier Ltd. doi: 10.1016/B978-0-08-100310-7.00003-X.

Kendall, H. et al. (2019) 'A systematic review of consumer perceptions of food fraud and authenticity: A European perspective', Trends in Food Science and Technology. Elsevier, 
94(October), pp. 79-90. doi: 10.1016/j.tifs.2019.10.005.

Lam, T. K., Heales, J., Hartley, N., \& Hodkinson, C. (2020). Consumer Trust in Food Safety Requires Information Transparency. Australasian Journal of Information Systems, 24.

Li, Y. et al. (2020) 'A Traceability Architecture for the Fresh Food Supply Chain Based on Blockchain Technology in China', in International Conference on Artificial Intelligence and Security. Springer, pp. 347-358.

Li, J., Li, N., Peng, J., Cui, H., \& Wu, Z. (2019). Energy consumption of cryptocurrency mining: A study of electricity consumption in mining cryptocurrencies. Energy, 168, 160-168.

Lin, K., Chavalarias, D., Panahi, M., Yeh, T., Takimoto, K., \& Mizoguchi, M. (2020). Mobilebased traceability system for sustainable food supply networks. Nature Food, 1(11), 673-679.

Mainetti, L. et al. (2013) 'An innovative and low-cost gapless traceability system of fresh vegetable products using RF technologies and EPCglobal standard', Computers and

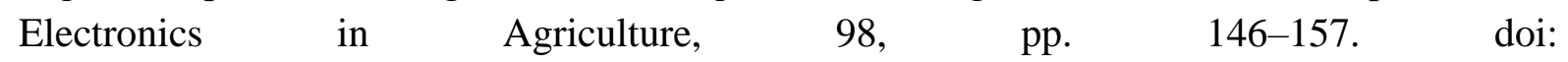
https://doi.org/10.1016/j.compag.2013.07.015.

Manning, L. (2019a) 'Corporate responsibility in a transitioning food environment: Truthseeking and truth-telling', in Food Tech Transitions. Springer, pp. 149-169.

Manning, L. (2019). Food defence: Refining the taxonomy of food defence threats. Trends in Food Science \& Technology, 85, 107-115.

El Maouchi, M., Ersoy, O. and Erkin, Z. (2018) 'TRADE: A transparent, decentralized traceability system for the supply chain', in Proceedings of 1st ERCIM Blockchain Workshop 2018. European Society for Socially Embedded Technologies (EUSSET).

Mattevi, M. and Jones, J. A. (2016) 'Food supply chain: Are UK SMEs aware of concept, drivers, benefits and barriers, and frameworks of traceability?', British Food Journal, 118(5), pp. 1107-1128. doi: 10.1108/BFJ-07-2015-0261.

McCathie, L. and Michael, K. (2005) 'Is it the end of barcodes in supply chain management?'

McLinden, T. et al. (2014) 'Component costs of foodborne illness: a scoping review', BMC Public Health. Springer, 14(1), pp. 1-12.

Mermelstein, N. H. (2015) 'Fighting Food Fraud', Institute of Food Technologists, pp. 67-73. https://www.ift.org/ /media/food\%20technology/pdf/2015/03/0315_col_foodsafetyquality.pd f. Accessed 20 January 2021

Microsoft Azure (nd). What is middleware? Available at: https://azure.microsoft.com/enus/overview/what-is-middleware/ Accessed 10 April 2021 
729 Mishra, N., Mistry, S., Choudhary, S., Kudu, S., \& Mishra, R. (2020). Food Traceability

730 System Using Blockchain and QR Code. In IC-BCT 2019 (pp. 33-43). Springer, Singapore.

731 Moe, T. (1998) 'Perspectives on traceability in food manufacture', Trends in Food Science \&

732 Technology, 9(5), pp. 211-214. doi: https://doi.org/10.1016/S0924-2244(98)00037-5.

733 Musa, A., Gunasekaran, A. and Yusuf, Y. (2014) 'Supply chain product visibility: Methods, 734 systems and impacts’, Expert Systems with Applications. Elsevier, 41(1), pp. 176-194.

735 Naylor, N. R. et al. (2017) 'A national estimate of the health and cost burden of Escherichia 736 coli bacteraemia in the hospital setting: the importance of antibiotic resistance', bioRxiv. Cold 737 Spring Harbor Laboratory, p. 153775.

738 Norton, T. et al. (2014) 'A guide to traceability', United Nations Global Compact Office, p. 739 45. Available at: https://www.bsr.org/reports/BSR_UNGC_Guide_to_Traceability.pdf.

740 Olsen, P. (2017) Food traceability in theory and in practice. Available at: 741 https://ninum.uit.no/handle/10037/15408.

742 Olsen, P. and Borit, M. (2013) 'How to define traceability', Trends in food science \& 743 technology. Elsevier, 29(2), pp. 142-150.

744 Olsen, P. and Borit, M. (2018) 'The components of a food traceability system', Trends in Food 745 Science and Technology. Elsevier, 77(June 2017), pp. 143-149. doi: 746 10.1016/j.tifs.2018.05.004.

747 Opara, L. U. (2003) 'Traceability in agriculture and food supply chain: a review of basic 748 concepts, technological implications, and future prospects'.

749 Óskarsdóttir, K. and Oddsson, G. V. (2019) 'Towards a decision support framework for 750 technologies used in cold supply chain traceability', Journal of Food Engineering. Elsevier, 751240, pp. 153-159.

752 Palmer, R. C. (1989) The bar code book: reading, printing, and specification of bar code 753 symbols. Helmers Pub.

754 Patil, V. C. et al. (2012) 'Internet of things (Iot) and cloud computing for agriculture: An 755 overview', Proceedings of agro-informatics and precision agriculture (AIPA 2012), India, pp. 756 292-296.

757 Pearson, S. et al. (2019) 'Are Distributed Ledger Technologies the panacea for food 758 traceability?', Global Food Security. Elsevier B.V., 20(November 2018), pp. 145-149. doi: $759 \quad 10.1016 /$ j.gfs.2019.02.002.

760 Qian, J., Ruiz-Garcia, L., Fan, B., Villalba, J. I. R., McCarthy, U., Zhang, B., ... \& Wu, W. 
(2020). Food traceability system from governmental, corporate, and consumer perspectives in the European Union and China: A comparative review. Trends in Food Science \& Technology, 99, 402-412.

Regattieri, A., Gamberi, M. and Manzini, R. (2007) 'Traceability of food products: General framework and experimental evidence', Journal of Food Engineering, 81(2), pp. 347-356. doi: 10.1016/j.jfoodeng.2006.10.032.

Reischach, F. von et al. (2011) 'Barcode scanners on the rise : Evaluation of 1D barcode scanning on mobile phones', Human Factors, pp. 2-5.

RFID4U. How to Select a Correct Tag - Frequency. Available at: https://rfid4u.com/rfidfrequency/ (Accessed: 29 December 2020).

Rodriguez-Salvador, B. and Dopico, D. C. (2020) 'Understanding the value of traceability of fishery products from a consumer perspective', Food Control. Elsevier, 112, p. 107142.

Ruiz-Garcia, L. et al. (2009) 'A Review of Wireless Sensor Technologies and Applications in Agriculture and Food Industry: State of the Art and Current Trends', Sensors . doi: $10.3390 / \mathrm{s} 90604728$.

Salah, K. et al. (2019) 'Blockchain-Based Soybean Traceability in Agricultural Supply Chain', IEEE Access, pp. 73295-73305. doi: 10.1109/ACCESS.2019.2918000.

Smith, G. C. et al. (2005) 'Traceability from a US perspective', Meat Science, 71(1), pp. 174193. doi: 10.1016/j.meatsci.2005.04.002.

Sterling, B. et al. (2015) 'Assessing the value and role of seafood traceability from an entire value-chain perspective', Comprehensive Reviews in Food Science and Food Safety. Wiley Online Library, 14(3), pp. 205-268.

Tan, J. and Koo, S. G. M. (2014) 'A survey of technologies in internet of things', in 2014 IEEE International Conference on Distributed Computing in Sensor Systems. IEEE, pp. 269-274.

Tarjan, L. et al. (2014) 'A readability analysis for QR code application in a traceability system', Computers and Electronics in Agriculture. Elsevier, 109, pp. 1-11.

Thakur, M. and Forås, E. (2015) 'EPCIS based online temperature monitoring and traceability in a cold meat chain', Computers and Electronics in Agriculture, 117, pp. 22-30. doi: https://doi.org/10.1016/j.compag.2015.07.006.

Tian, F. (2017) 'A supply chain traceability system for food safety based on HACCP, Blockchain \& Internet of things', in 2017 International conference on service systems and service management. IEEE, pp. 1-6. 
793

794

795

796

797

798

799

800

801

802 Wilcock, A. et al. (2004) 'Consumer attitudes, knowledge and behaviour: a review of food

803

804 World Economic Forum (2019) Innovation with a purpose: Improving traceability in food

805 value chains through technology innovations.

806 Yang, S.-C. et al. (2017) 'Current pathogenic Escherichia coli foodborne outbreak cases and

807 therapy development', Archives of Microbiology. Springer, 199(6), pp. 811-825.

808 Zhang, A., Mankad, A., \& Ariyawardana, A. (2020). Establishing confidence in food safety: is

809 traceability a solution in consumers' eyes?. Journal of Consumer Protection and Food 810 Safety, 15(2), 99-107.

811 Zhang, J. and Bhatt, T. (2014) 'A Guidance Document on the Best Practices in Food

812 Traceability', Comprehensive Reviews in Food Science and Food Safety, 13(5), pp. 1074813 1103. doi: 10.1111/1541-4337.12103.

814 Zhang, X. et al. (2010) 'Strengths and limitations on the operating mechanisms of traceability 815 system in agro food, China’, Food Control. Elsevier, 21(6), pp. 825-829. 